\title{
Progress in protecting non-smokers from environmental tobacco smoke in California workplaces
}

\author{
Christi A Patten, John P Pierce, Shirley W Cavin, Charles C Berry, Robert M Kaplan
}

\begin{abstract}
Objective - To evaluate changes in workplace smoking policies and reported nonsmoker exposure to environmental tobacco smoke in California workplaces.

Design-Data were gathered using the California Tobacco Survey, which was conducted among 13199 adult indoor workers in 1990, 5570 in 1992, and 15745 in 1993.

Results-Between 1990 and 1993, the percentage of indoor employees reporting smoke-free workplaces increased significantly from $35.0 \%$ to $64.6 \%$. In 1993 , nearly $90 \%$ of employees reported a work area smoking ban as compared to only $54 \%$ of workers in 1990 . Reported environmental tobacco smoke exposure decreased significantly among nonsmoking indoor employees. Non-smokers in workplaces without a work area smoking policy were 15 times more likely to be exposed to environmental tobacco smoke than were non-smokers in a smoke-free workplace. Among nonsmokers employed in smoke-free workplaces, reported environmental tobacco smoke exposure declined from $9.2 \%$ in 1990 to $4.0 \%$ in 1992 , but increased to $11.2 \%$ in 1993.
\end{abstract}

Conclusions - The increase in smoke-free policies has considerably reduced the proportion of non-smokers exposed to environmental tobacco smoke in California workplaces. In addition, compliance with smoke-free policies was nearly $90 \%$ in the three years surveyed. The data also suggest that only smoke-free workplaces adequately protect nonsmokers.

\section{(Tobacco Control 1995; 4: 139-144)}

Keywords: smoking; workplace; smoking policies; environmental tobacco smoke

\section{Introduction}

Actions to protect the non-smoker from environmental tobacco smoke exposure in the workplace have increased considerably..$^{1-3} \mathrm{By}$ 1992, 413 city and local ordinances mandating the adoption of workplace smoking policies had been enacted in the United States. ${ }^{4}$ More than half of these were adopted in California, where more than 50 ordinances prohibited smoking in common work areas, and 32 mandated $100 \%$ smoke-free workplaces. The January 1993 release of the Environmental Protection Agency (EPA) report, ${ }^{5}$ which classified environmental tobacco smoke as a known human carcinogen, provided a compelling reason for local governments to strengthen ordinances and for employers to implement workplace smoking policies to avoid possible future liability. ${ }^{6-8}$

The increasing trend toward smoke-free workplaces should have a positive impact on protecting non-smokers from exposure to environmental tobacco smoke.$^{9-11}$ In a previous report, ${ }^{9}$ we observed that in workplaces with no policy or a policy not covering the work area, non-smokers were more than eight times more likely to be exposed to environmental tobacco smoke than those who worked in a smoke-free workplace.

Several studies have shown that smoking policies that are implemented over an extended period receive considerable support from employees and achieve high levels of compliance. ${ }^{12-14}$ Thus a transition period may be necessary before a newly implemented smoking policy will make a substantial difference in protecting non-smokers from environmental tobacco smoke.${ }^{15-17}$ However, the recent legal and legislative pressures to protect nonsmokers may have led employers to discard this transition period and mandate at least a work area ban on smoking with a very proximal or immediate implementation date. ${ }^{18-20}$ If this phenomenon occurred after the EPA report was released, then compliance with smoking bans may lag behind such policies.

Despite the recent proliferation of workplace smoking policies, few studies have evaluated changes in environmental tobacco smoke exposure over time. In this study, we evaluate changes in workplace smoking policies and reported environmental tobacco smoke exposure among non-smokers in Californian workplaces. Data are examined from a large population survey conducted among Californian indoor workers in 1990, 1992, and 1993. The 1993 data were collected following the final publication of the EPA report.

\section{Methods}

As part of a population based telephone survey 
using a random digit dial method, ${ }^{21}$ we interviewed 13199 Californian indoor workers in 1990, 5570 in 1992, and 15745 in 1993. The response rates to the household surveys were $75 \%, 73 \%$, and $70 \%$, respectively. The design of the three surveys differed with respect to the proportion of non-smokers sampled. The 1990 and 1993 surveys had large sample sizes, adequate for detecting differences in smoking behaviour at the regional level within California, whereas the 1992 survey used a much smaller sample, sufficient only to assess smoking behaviour at the statewide level. Sample sizes for non-smokers were 8580 in 1990, 2177 in 1992, and 12946 in 1993. Data were weighted to handle the different probabilities of selection; to represent the Californian population with respect to gender, race/ethnicity, age, and education level; and to provide comparable estimates of behaviour changes in Californians. A description of the in-depth interview and details of the survey design, weighting, and variance estimation are reported elsewhere. ${ }^{922-23}$

The telephone interview included questions on demographics, smoking behaviour, employment status and type, and workplace smoking policy. Exposure to environmental tobacco smoke was assessed with the question, "During the past two weeks has anyone smoked in the area in which you work?"

The type and extent of smoking restrictions in the respondent's workplace were determined using the following three questions in 1990 and 1992: "Does your employer have an official policy that restricts smoking in any way?" Those indicating "yes" were then asked, "Which of the following best describes your employer's smoking policy for indoor public or common areas, such as lobbies, rest rooms, and lunch rooms?" and "Which of the following best describes your employer's smoking policy for areas in which employees work?" Possible response choices for the last two questions included: (1) not allowed in any, (2) allowed in some, and (3) allowed in all. A single question was asked in 1993: "Which of the following best describes your employer's smoking policy for indoor work and public or common areas? Would you say that smoking is (1) not allowed in any part of the indoor work area, (2) not allowed in any indoor work area but is allowed in some public or common areas, or (3) allowed in indoor work areas?"

Californian indoor workplaces were divided into three categories representing the degree of workplace smoking restriction. We defined a workplace as either smoke-free (smoking not allowed in any work areas or any common areas in the workplace), having a work area ban (smoking not permitted in any work areas but allowed in some or all common areas), or having lesser or no work area smoking restrictions.

Changes in Californian workplace policies were analysed for all workers (smokers and non-smokers) who were employed indoors outside the home, while analyses examining exposure to environmental tobacco smoke were restricted to non-smoking indoor workers.
Data analyses were conducted using the SAS statistical package. ${ }^{24}$ Variance estimation was based on the jackknife procedure ${ }^{25}$ using 51 subsample replicates and comparing the deviations of these estimates from those obtained from the full sample. Logistic regression was used to assess whether different independent variables (demographics, workplace smoking policy) were related to environmental tobacco smoke exposure. Confidence intervals for statistics of interest and for odds ratios derived from the logistic regression were computed using the jackknife procedure. Analysis of the change in rate of conversion to smoke-free workplaces used rate equations of the form $e^{-\lambda t}$, where $t$ is time and $\lambda$ is the rate constant. Variance for $\lambda_{1}-\lambda_{2}$ was calculated using the delta method. ${ }^{26}$

\section{Results}

CHANGES IN WORKPLACE SMOKING POLICY

Between 1990 and 1993, the overall percentage of Californian indoor employees reporting smoke-free workplaces increased significantly, from $35.0 \%$ to $64.6 \%$ (figure). Correspondingly, the percentage of employees reporting workplaces without work area smoking bans declined from $46.0 \%$ in 1990 to $12.7 \%$ in 1993. The figure also shows that between 1992 and 1993, the establishment of smoke-free workplace policies accelerated from the rate of increase before 1992. In the 10 months between the 1992 and 1993 surveys, smoke-free workplace policies grew by $50 \%$, more than five times the average annual increase from 1990 to 1992 ( $\mathrm{p}<0.001$ ).

The increase in smoke-free policies from 1990 to 1993 was observed across all demographic subgroups (table 1). These increases were all significant between 1992 and 1993. In contrast, from 1990 to 1992 the observed changes were smaller and were non-significant for some subgroups including black and Hispanic workers, those with less than a high school education, and workers who were younger than 25 years of age.

Despite increases in smoke-free policies for all demographic subgroups from 1990 to 1993 , some groups of indoor employees were more likely than others to work in a smoke-free workplace in $1993(\mathrm{p}<0.05)$. Women were more likely than men to report employment in a smoke-free workplace; workers 25 years of age and older were more likely to work in a smoke-free workplace compared to younger workers; and workers of non-Hispanic ethnic/ racial origin were more likely to report employment in a smoke-free workplace $(66.1 \%)$ than were Hispanic workers $(58.4 \%)$. Finally, those who had attended college were more likely to be employed in a smoke-free workplace $(69.5 \%)$ than those with no college education $(57.9 \%)$.

REPORTED EXPOSURE OF NON-SMOKERS TO ENVIRONMENTAL TOBACCO SMOKE

Non-smoking indoor workers reported a marked reduction in exposure to environ- 


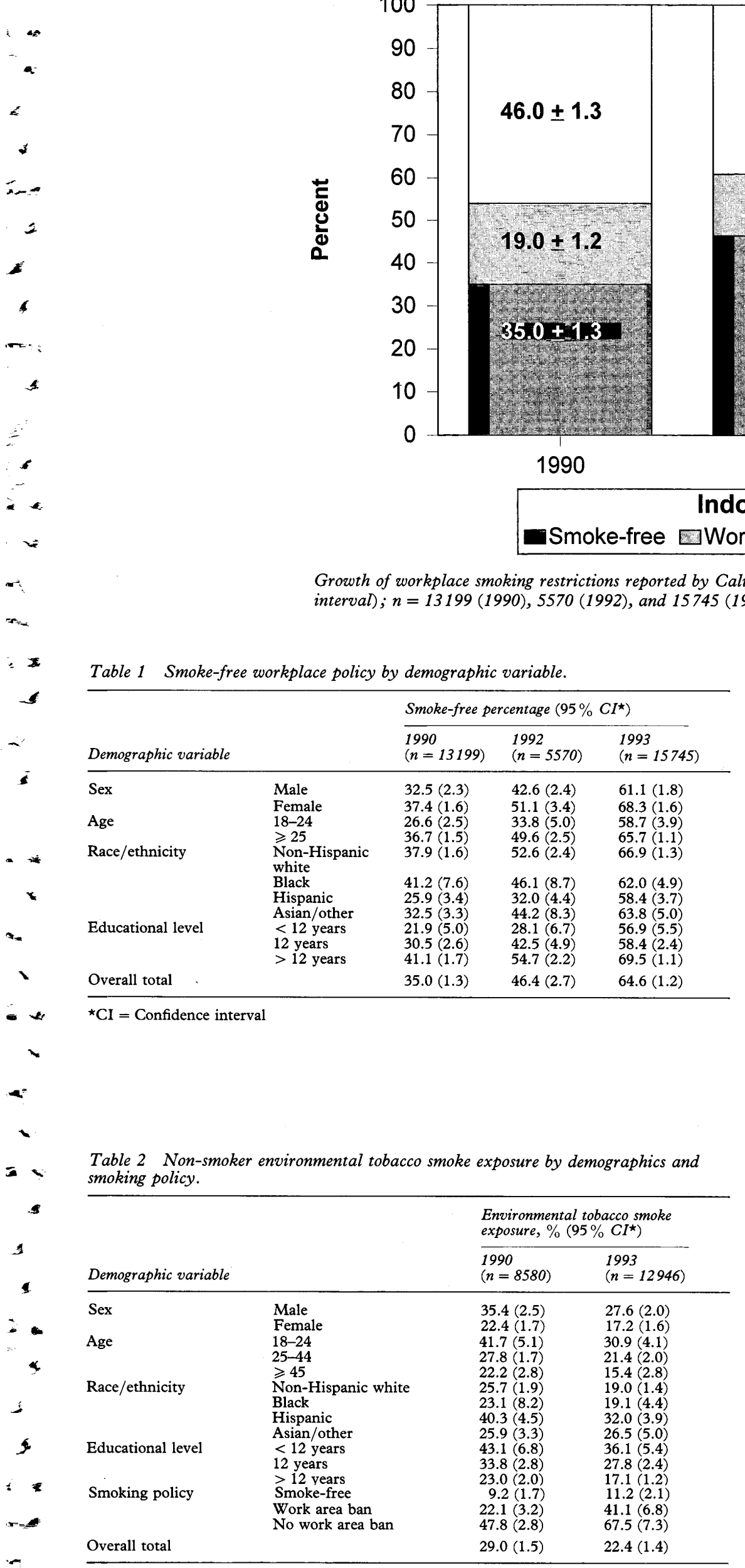

* $\mathrm{CI}=$ Confidence interval

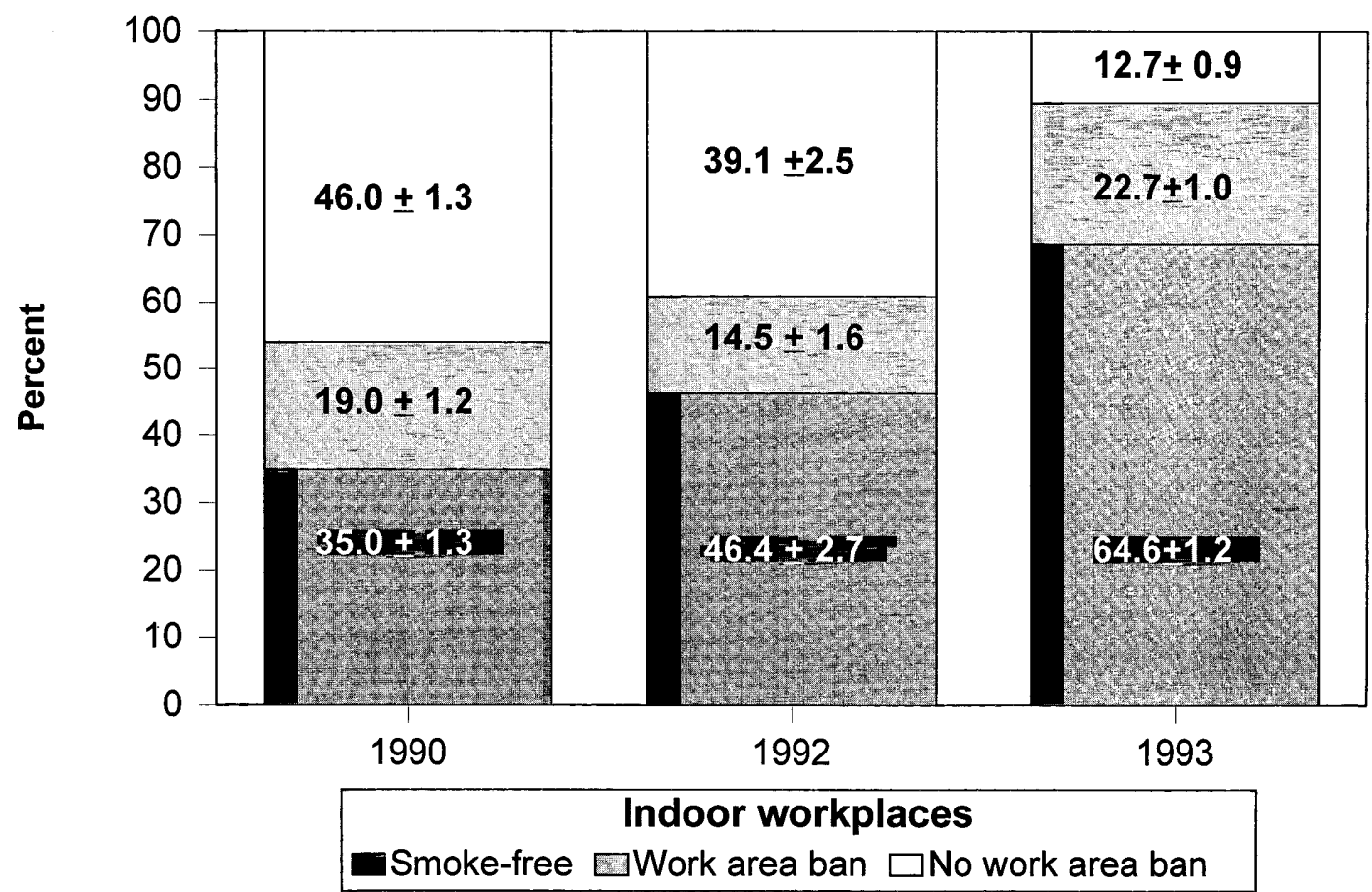

Growth of workplace smoking restrictions reported by Californian workers, 1990-1993 (\% $195 \%$ confidence interval); $n=13199$ (1990), 5570 (1992), and 15745 (1993).

mental tobacco smoke from 1990 to 1993. In $22.4 \%$ reported exposure in 1993 (an estimated 1.83 million people) (table 2). Table 2 presents non-smoker report of environmental tobacco smoke exposure as a function of $1990,29.0 \%$ of non-smokers (an estimated 2.22 million people) were exposed to environmental tobacco smoke at work, whereas only demographics. Excepting three subgroups (blacks, Asians, and those with less than a high school education), every demographic subgroup reported significant reductions in environmental tobacco smoke exposure between 1990 and 1993.

In 1993, higher levels of environmental tobacco smoke exposure were related to several demographic variables (table 2). Exposure to environmental tobacco smoke was significantly more likely $(\mathrm{p}<0.05)$ among males than among females, among adult workers younger than 25 years than among older workers, and among Hispanics and Asians than among whites. Furthermore, workers with less than a high school education reported an exposure rate of $36.1 \%$ as compared to $27.8 \%$ of those with a high school education, and $17.1 \%$ of those who had attended college.

COMPLIANCE

We examined compliance with smoke-free policies by determining environmental tobacco smoke exposure among non-smokers who were employed in smoke-free workplaces. Overall, compliance with smoke-free policies was nearly $90 \%$ during the three years surveyed. From 1990 to 1992, reported exposure to environmental tobacco smoke in workplaces with policies declined from $9.2 \%$ to $4.0 \%$. In 1993, reported exposure increased to $11.2 \%$. 
Table 3 Odds ratios for non-smoker environmental tobacco smoke exposure.

\begin{tabular}{llll}
\hline & & \multicolumn{2}{l}{ Odds ratios $\left(95 \% C I^{\star}\right)$} \\
\cline { 3 - 4 } Demographic variable & & $\begin{array}{l}1990 \\
(n=8580)\end{array}$ & $\begin{array}{l}1993 \\
(n=12946)\end{array}$ \\
\hline Sex & Male & 1.0 & 1.0 \\
Age & Female & $0.52(0.43-0.64)$ & $0.58(0.49-0.68)$ \\
& $18-24$ & 1.0 & 1.0 \\
Race/ethnicity & $25-44$ & $0.66(0.51-0.86)$ & $0.76(0.59-0.97)$ \\
& Non-Hispanic white & $1.07(0.36-0.63)$ & $0.52(0.38-0.72)$ \\
& Black & $0.89(0.55-1.44)$ & $0.87(0.61-1.24)$ \\
Educational level & Hispanic & $1.35(1.01-1.81)$ & $1.46(1.14-1.88)$ \\
Smoking policy & Asian/other & $0.95(0.75-1.18)$ & $1.50(1.13-1.97)$ \\
& No college & 1.0 & 1.0 \\
& College & $0.66(0.55-0.79)$ & $0.60(0.51-0.70)$ \\
& Smoke-free & 1.0 & 1.0 \\
& Work area ban & $2.69(1.90-3.80)$ & $3.74(2.80-4.98)$ \\
& No work area ban & $8.26(5.51-12.36)$ & $15.09(9.80-23.22)$ \\
\hline
\end{tabular}

$\star \mathrm{CI}=$ Confidence interval smoking ban, compared to only $54 \%$ of workers in 1990. The changes in smoke-free policies markedly affected all demographic subgroups.

We recognise that it is not possible to determine a causal relationship between changes in workplace smoking policies and the final publication of the EPA report. However, our data, collected in the six months after the EPA report was released, suggest that smokefree policies may have increased rapidly during this period. Between 1990 and 1992, the annual rate of increase in smoke-free workplaces was $10 \%$. In contrast, between 1992 and 1993, the proportional increase in smoke-free workplaces was five times higher $(50 \%)$.

In addition to the release of the EPA report, other factors may have contributed to the increase in smoke-free policies in Californian workplaces. For example, the majority of city and local ordinances that mandate the adoption of workplace smoking policies have been enacted in California; we have previously shown that strong local smoking ordinances increase the likelihood that workplaces will have smoke-free policies. ${ }^{27}$ Alternatively, employers motivated by economic, medical, or legal concerns may voluntarily implement a smoke-free policy. ${ }^{28}$ Nevertheless, our data raise interesting questions regarding how California differs from other states in terms of workplace smoking restrictions. Further studies are warranted in which such comparisons would be examined.

The strengths of our study include the use of a large population based survey, coupled with the many tobacco control policies that have been occurring over time in California, which allowed us to examine environmental tobacco smoke exposure as a function of workplace smoking policy. Thus we were able to show that increases in workplace smoking policies have led to a considerable reduction in the proportion of non-smokers who are exposed to environmental tobacco smoke. Overall, an estimated 1.83 million non-smoking Californians were exposed to environmental tobacco smoke at work in 1993 compared to an estimated 2.22 million in 1990, indicating a major reduction in levels of exposure.

These reductions in environmental tobacco smoke exposure affected almost all demographic subgroups. However, no significant decreases were detected among black or Asian workers, or those without a high school education. One explanation for this finding is that smoking may be more prevalent in workplaces that employ workers with these characteristics. Alternatively, these workers might be more likely to work in open work areas or for smaller companies. Some data suggest that smaller firms are less likely to have a smoke-free policy. ${ }^{1}$

Consistent with our previous report, ${ }^{9}$ the type of workplace smoking policy had a large effect on protecting non-smokers from environmental tobacco smoke exposure. In 1993, in workplaces with no policy or a policy not covering the work area, non-smokers were 15 times more likely to be exposed to environ- 
mental tobacco smoke than were non-smokers in a smoke-free workplace. Although a work area ban offered more protection than did the absence of such a ban, non-smokers who worked under a work area ban were nearly four times more likely to report exposure to environmental tobacco smoke than were nonsmokers in a smoke-free workplace. These findings further strengthen our previous observation that only smoke-free workplaces provide adequate protection of non-smokers. ${ }^{9}$

Our findings suggest that compliance with smoke-free policies was high during the three years surveyed. Among non-smokers who worked in a smoke-free workplace, reported environmental tobacco smoke exposure declined from $9.2 \%$ in 1990 to $4.0 \%$ in 1992 , but then increased to $11.2 \%$ in 1993 . The reduction in environmental tobacco smoke exposure from 1990 to 1992 suggests that a transition period may be necessary before a newly implemented policy will make a notable difference in protecting non-smokers from environmental tobacco smoke.

The increase in reported environmental tobacco smoke exposure from 1992 to 1993 may be attributed to several factors. This finding may be explained by the large number of new policies that appear to have been implemented during this time. If smoking policies were implemented in response to the EPA report, these policies would have been in force for only a brief period before the survey. Employers may have implemented policies without allowing employee smokers sufficient time to adjust their addictive behaviour. However, 1993 environmental tobacco smoke exposure levels in smoke-free workplaces only reverted to levels observed in 1990 . On the basis of previous studies, we hypothesise that there may be a transition or acclimatisation period that lasts between six and 12 months. ${ }^{13-15}$ Another factor that may account for the increase in reported environmental tobacco smoke exposure from 1992 to 1993 is that, as smoking becomes less common and environmental tobacco smoke exposure is reduced in the workplace, workers are no longer acclimatised to environmental tobacco smoke and are more likely to recognise their exposure.

This study relied on self report data of smoking status, workplace policy, and environmental tobacco smoke exposure. In another study, ${ }^{29}$ adequate reliability was found for questions on smoking behaviour which were similar to those used in our survey. However, due to the population-based nature of our survey, we had no opportunity to assess the reliability or conduct validations of self reported workplace smoking policy and environmental tobacco smoke exposure. A previous report showed that workers who reported the presence of a smoke-free workplace were likely to be covered by a strong local smoking ordinance..$^{27}$ However, the reliability and validity of self report data of this nature needs further study.

In conclusion, the increase in smoke-free policies in Californian workplaces has led to a considerable reduction in the proportion of non-smokers who are exposed to environmental tobacco smoke. Compliance with smoke-free policies is remarkably high but may lag behind policy implementation when many new policies are established without a sufficient transition period. This study also shows that only smoke-free workplaces protect non-smokers adequately. With the final publication of the EPA report, employers who have not developed a smoke-free policy may be susceptible to possible future liability. Although legal risks for failing to institute a smoking policy are increasing, future efforts must be continually directed toward establishing more stringent state and national regulations as well as local smoking ordinances that require smoke-free workplaces to protect the health of non-smokers. Public health efforts should also focus on working directly with employers by educating them on the benefits and process of establishing a smoke-free work environment.

This study was supported by contracts $89-97872$ and $92-16010$ from the California Department of Health Services, Tobacco Control Section, Sacramento, California, USA. CAP is an American Heart Association Established Investigator.

1 Bureau of National Affairs. Smoking in the workplace. Washington, DC: BNA, 1991. (Bulletin to Managemen (SHRM-BNA Survey No 55), 1-2.)

2 US Department of Health and Human Services. The health consequences of involuntary smoking. $A$ report of the Surgeon General, 1986. Rockville, Maryland: Public Health Service, Centers for Disease Control, 1986 (DHHS Publication No (CDC) 87-8398.)

3 Rigotti NA, Pashos CL. No-smoking laws in the United States: an analysis of state and city actions to limit smoking in public places and workplaces. $\mathscr{F} A M A 1991$ 266: 3162-7.

4 Pertschuk M, Shopland DR, eds. Major local tobacco control ordinances in the United States. Smoking and tobacco control monograph 3. Bethesda, Maryland: US Department of Health and Human Services, Public Health Service, National Institutes of Health, National Cancer Institute, 1993. (NIH Publication No 93-3532.)

5 US Environmental Protection Agency. Respiratory health effects of passive smoking: lung cancer and other disorders. Washington, DC: Office of Health and Environmenta Assessment, 1992. (Publication No EPA/600/6-90006F.)

6 Bureau of National Affairs. EPA releases draft reports on passive smoke: urges employers to implement smokin policy. Occup Saf Health Rep June 27, 1990: 124-5.

7 Roan S. Secondhand smoke still a risk on the job (JAMA report). Los Angeles Times Aug 12, 1992: A3.

8 Smith B. EPA reports on passive smoking hazards. Occup Health Saf 1993; 8: 10.

9 Borland R, Pierce JP, Burns DM, Gilpin E, Johnson M, Bal D. Protection from environmental tobacco smoke in California: the case for a smoke-free workplace. $¥ A M A$ 1992; 268: 749-52.

10 Marcus BH, Emmons KM, Abrams DB, Marshall RJ, Kane $M$, Novotny TE, et al. Restrictive workplace smoking policies: impact on non-smokers' tobacco exposure. F Public Health Policy 1992; 13: 42-51.

11 Repace JL. Passive smoking is risky. 7 Am Med Wom Assoc $1989 ; 44: 50-4$

12 Action plan to encourage union support for a smoke-free hospital. Minn Med 1987; 70: 654-5.

13 Hurt RD, Berge KG, Offord KP, Leonard DA, Gerlach DK, Renquist CL, et al. The making of a smoke-free medical center. $7 A M A 1989 ; 261: 95-7$.

14 Stillman FA, Becker DM, Swank RT, Hantula D, Moses $\mathrm{H}$, Glantz S, et al. Ending smoking at the Johns Hopkins Medical Institutions: an evaluation of smoking preMedical Institutions: an evaluation of smoking pre-
valence and indoor air pollution. $\mathfrak{F} A M A 1990 ; 264$ : valence

15 Knapp J, Silvis G, Sorensen G, Kottke T. Clean air health care: a guide to establish smoke-free health care facilities. Minneapolis: University of Minnesota, 1986.

16 American Hospital Association. Smoking and hospitals... are a bad match! Policy development and implementation strategies for a smoke-free environment. Chicago: American Hospital Association, 1988.

17 US Department of Health and Human Services. No smoking: a decision maker's guide to reducing smoking at the worksite. Rockville, Maryland. Public worksite. Rockville, Maryland: Public Health Service Office on Smoking and Health, 1985. 
18 Lesmes GR, Donofrio KH. Passive smoking: the medical and economic issues. Am F Med 1992; 93 (suppl 1A) 38-42S.

19 US Department of Health and Human Services. Strategies to control tobacco use in the United States: a blueprint for public health action in the 1990 s. Bethesda, Maryland: US Public Health Service, National Institutes of Health Public Health Service, National Institutes of Health, 92-3316.)

20 Voluck PR. The work environment: burning legal issues of smoking in the workplace. Personnel $f$ 1987; 50:140-3.

21 Waksberg J. Sampling methods for random digit dialing. Am Stat Assoc 1978; 73: 40-6.

22 Pierce JP, Goodman J, Gilpin EA, Berry C. Technical report on analytic methods and approaches used in the tobacco use survey in California, 1990-1991 report. Sacramento, California: California Department of Health Services, 1992

23 Woodruff TJ, Rosbrook B, Pierce JP, Glantz SA. Lowe levels of cigarette consumption found in smoke-free workplaces in California. Arch Intern Med 1993; 153: workplaces
24 SAS Institute, Inc. $S A S / S T A T^{\mathrm{TM}}$ user's guide, release 6.03 edition. Cary, NC: SAS Institute, 1988.

25 Efron $\mathrm{B}$. The jackknife, the bootstrap and other resampling plans. Philadelphia: Society for Industrial and Applied Mathematics, 1982. (CBMS regional conference series in applied mathematics, 38 .)

26 Rao CR Linear statistical inference and its applications. 2nd ed. New York: John Wiley and Sons, 1973: 388. (Wiley series in probability and mathematical statistics.

27 Pierce JP, Shanks TG, Pertschuk M, Gilpin E, Shopland $\mathrm{D}$, Johnson $\mathrm{M}$, et al. Do smoking ordinances protect nonsmokers from environmental tobacco smoke at work? Tobacco Control 1994; 3: 15-20.

28 Erickson MP. Workplace smoking control: rationale and approaches. Adv Health Educ Promotion 1986; 1: 65-103.

29 Brownson RS, Jackson-Thompson J, Wilkerson JC, Kiani F. Reliability of information on chronic disease risk factors collected in the Missouri behavioral risk factor surveillance system. Epidemiology 1994; 5: 545-9.

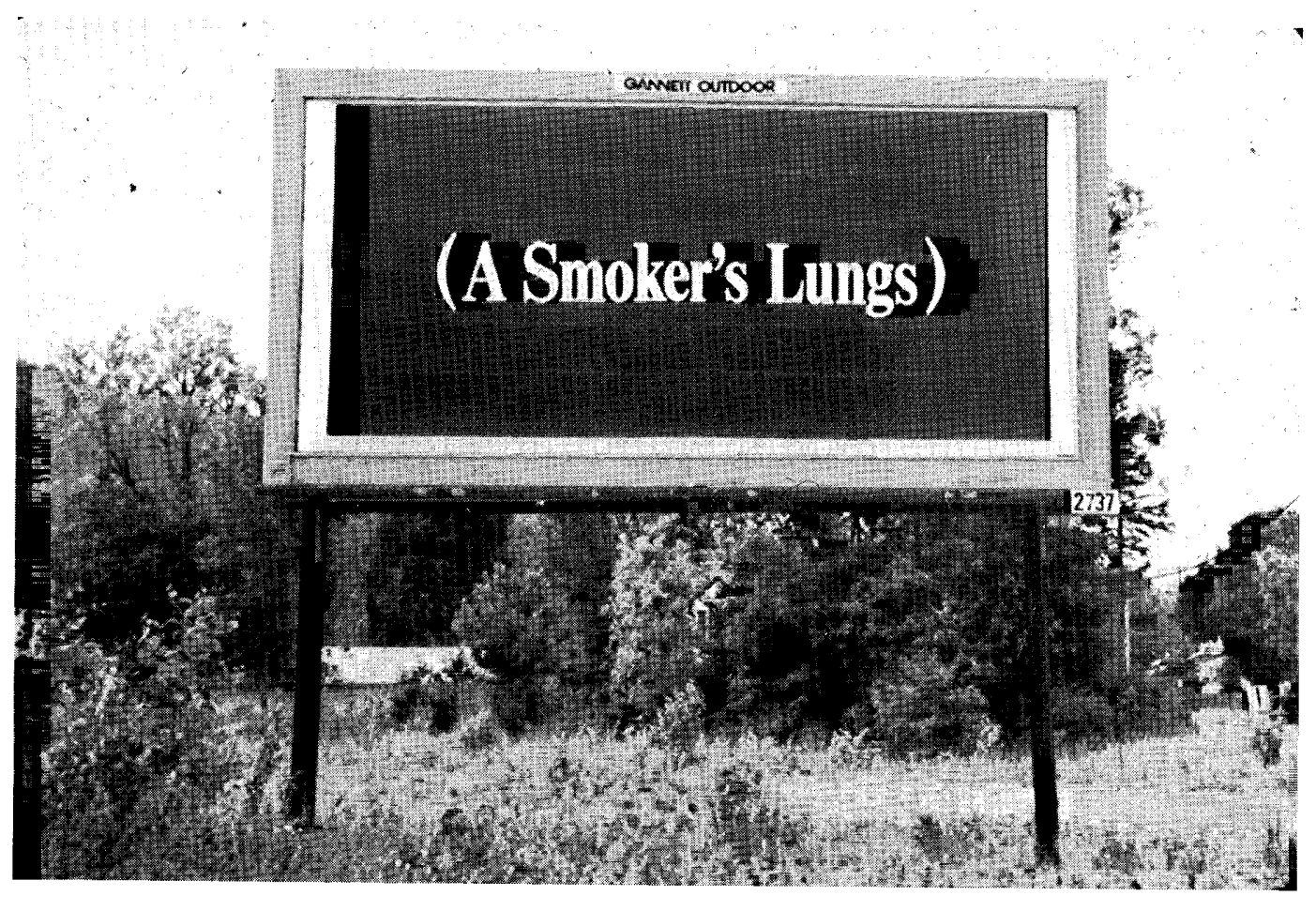

